\title{
Fluid shear stress modulation of hepatocyte-like cell function
}

\author{
Hassan Rashidi ${ }^{1} \cdot$ Sharmin Alhaque $^{1} \cdot$ Dagmara Szkolnicka $^{1} \cdot$ Oliver Flint $^{1} \cdot$ \\ David C. Hay ${ }^{1}$ [D
}

Received: 31 January 2016 / Accepted: 25 February 2016 / Published online: 15 March 2016

(c) The Author(s) 2016. This article is published with open access at Springerlink.com

\begin{abstract}
Freshly isolated human adult hepatocytes are considered to be the gold standard tool for in vitro studies. However, primary hepatocyte scarcity, cell cycle arrest and the rapid loss of cell phenotype limit their widespread deployment. Human embryonic stem cells and induced pluripotent stem cells provide renewable sources of hepatocyte-like cells (HLCs). Despite the use of various differentiation methodologies, HLCs like primary human hepatocytes exhibit unstable phenotype in culture. It has been shown that the functional capacity can be improved by adding back elements of human physiology, such as cell co-culture or through the use of natural and/ or synthetic surfaces. In this study, the effect of fluid shear stress on HLC performance was investigated. We studied two important liver functions, cytochrome P450 drug metabolism and serum protein secretion, in static cultures and those exposed to fluid shear stress. Our study demonstrates that fluid shear stress improved Cyp1A2 activity by approximately fivefold. This was paralleled by an approximate ninefold increase in sensitivity to a drug, primarily metabolised by Cyp2D6. In addition to metabolic capacity, fluid shear stress also improved hepatocyte phenotype with an approximate fourfold reduction in the secretion of a foetal marker, alpha-fetoprotein. We believe these studies highlight the importance of introducing physiologic cues in cell-based models to improve somatic cell phenotype.
\end{abstract}

David C. Hay

davehay@talktalk.net

1 MRC Centre for Regenerative Medicine, University of Edinburgh, Edinburgh EH16 4UU, UK
Keywords Fluid shear stress · Hepatocyte-like cell · Embryonic stem cell · Cytochrome P450 Metabolism . Albumin secretion · Alpha-fetoprotein secretion

\section{Introduction}

Static and two-dimensional (2D) culture systems have been used extensively to study human biology. Although those systems are facile and cost-effective to use, they lack the complexity of the three-dimensional (3D) tissue microenvironment. As a result, those systems do not accurately model tissue physiology and can generate inaccurate datasets. It is a well-known phenomenon that cells respond to physical and chemical stimuli provided by the tissue niche (Rashidi et al. 2014). Therefore, the add-back of human physiology to cell based models is of the utmost importance. This will likely lead to an improvement in cell phenotype and more informative biological readouts from those systems (Godoy et al. 2015).

Fluid shear stress is one mechanical stimulus that is absent in static culture systems. The role of fluid transport is fundamental for organogenesis (Freund et al. 2012), cell signalling (Mammoto and Ingber 2010) and normal patterns of organ function (Hahn and Schwartz 2009; Hildebrandt et al. 2011). Living cells possess the ability to sense mechanical forces and transduce those into biological responses (Bao and Suresh 2003; Freund et al. 2012). The mechanisms that modulate cell behaviour by fluid shear stress is diverse, but is mediated primarily through cell surface receptors (Tzima et al. 2001), cell adhesion molecules (Tzima et al. 2005) and heterodimeric G proteins (White and Frangos 2007).

The effects of fluid shear stress have also been studied in primary hepatocytes and transformed hepatocyte cell lines. 
In these studies, fluid shear stress has been shown to modulate cell viability (Park et al. 2008; Tilles et al. 2001) and significantly alter hepatocyte cytochrome $\mathrm{P} 450$ gene expression (Mufti et al. 1995; Mufti and Shuler 1996; Roy et al. 2001; Shvartsman et al. 2009; Vinci et al. 2011). In this study, the effect of fluid shear stress on human embryonic stem cell (hESC) derived HLC function was evaluated.

\section{Materials and methods}

\section{Cell culture}

hESCs (H9) were cultured as previously described (Szkolnicka et al. 2013, 2014a). Human ESCs were plated onto Matrigel ${ }^{\circledR}$-coated $\quad\left(\right.$ Corning $^{\circledR}$ ) Thermanox ${ }^{\mathrm{TM}}$ coverslips (Nunc). Monolayer differentiation was initiated at $40 \%$ confluence by replacing serum-free medium mTESR 1 (STEMCELL Technologies) with endoderm differentiation medium: RPMI 1640 containing $1 \times$ B27 (Life Technologies), $100 \mathrm{ng} / \mathrm{ml}$ activin A (PeproTech) and $50 \mathrm{ng} / \mathrm{ml}$ Wnt3a (R\&D Systems). The medium was changed every $24 \mathrm{~h}$ for $72 \mathrm{~h}$. On day 4, endoderm differentiation medium was replaced with hepatoblast differentiation medium, and this was renewed every second day for a further 5 days. The medium consisted of knockout (KO)-DMEM (Life Technologies), serum replacement (Life Technologies), $0.5 \%$ Glutamax (Life Technologies), $1 \%$ non-essential amino acids (Life Technologies), $0.2 \%$ b-mercaptoethanol (Life Technologies) and $1 \%$ DMSO (Sigma). On day 9, differentiating cells were cultured in the hepatocyte maturation medium HepatoZYME (Life Technologies) containing $1 \%$ Glutamax (Life Technologies), supplemented with $10 \mathrm{ng} / \mathrm{ml}$ hepatocyte growth factor (PeproTech) and $20 \mathrm{ng} / \mathrm{ml}$ oncostatin M (PeproTech) as described previously (Szkolnicka et al. 2014a). To differentiate HLCs in 3D, a single cell suspension of $\mathrm{H} 9 \mathrm{hESCs}$ was prepared as previously described (Szkolnicka et al. 2014a). H9s were re-suspended in mTESR1 medium containing ROCK inhibitor (Merck) at concentration of $1.9 \times 10^{5}$ cells $/ \mathrm{ml}$. To form spheroids, $40 \mu \mathrm{l}$ of the cell suspension was transferred into Perfecta $3 \mathrm{D}^{\circledR}$ plates (Biomatrix, USA) using a multichannel pipette. The following day, 3D cell cultures were transferred into Corning ${ }^{\circledR} \operatorname{Costar}^{\circledR}$ Ultra-Low attachment multiwell plates and differentiated as previously described (Szkolnicka et al. 2014a). Spheroids were transferred at day 14 into a 24 -well plate containing Matrigel-coated Thermanox ${ }^{\mathrm{TM}}$ (Nunc) coverslips and allowed to adhere prior to exposure to fluid shear stress.

\section{Quasi-vivo $^{\circledR}$ system set-up}

Following 18 days of differentiation, HLCs grown on Thermanox ${ }^{\mathrm{TM}}$ coverslips were transferred into serially connected chambers of the Quasi-Vivo ${ }^{\circledR}$ system (Kirkstall Limited, UK). The fluid shear stress system was transferred into a humidified $37 \mathrm{C}, 5 \% \mathrm{CO} 2$ incubator, and fluid shear stress was applied at $2.9 \times 10^{-5}$ and $4.7 \times 10^{-5}$ dynes $/ \mathrm{cm}^{2}$ for $18 \mathrm{~h}$. Following fluid shear stress, cell populations were transferred to a 24-well plate for biochemical analysis.

\section{Cytochrome P450 assays}

Eighteen hours post-fluid shear stress, Cyp1A2 metabolic activity was measured using pGlo technology (Promega) and carried out according to the manufacturer's instructions (Cameron et al. 2015). Cyp1A2 activity was expressed as relative light units (RLUs) per millilitre of medium per milligram of protein (BCA assay, Pierce) per $5 \mathrm{~h}$. Levels of significance were measured by Student's $t$ test. The experiments are representative of three biological replicates.

\section{Cell viability assays}

Eighteen hours post-fluid shear stress, cell viability was measured using Cell Titer Glo (Promega) and carried out according to the manufacturer's instructions (Szkolnicka et al. 2014b). ATP levels were expressed as relative light units (RLUs) per millilitre of cell culture medium. Levels of significance were measured by Student's $t$ test. The experiments are representative of three biological replicates.

\section{Albumin and alpha-fetoprotein ELISA}

Eighteen hours post-fluid shear stress, HLC alpha-fetoprotein and albumin secretion were measured using commercially available ELISA kits (Alpha Diagnostic International). Protein secretion was expressed as microgram of protein per millilitre of medium per milligram of protein per $24 \mathrm{~h}$. Levels of significance were measured by Student's $t$ test. The experiments are representative of three biological replicates.

\section{Results}

The effect of fluid shear stress (FSS) on stem cell-derived HLC metabolic activity was studied using the Quasi-Vivo ${ }^{\circledR}$ system (Kirkstall Limited, UK). HLCs were exposed to FSS, ranging from $2.9 \times 10^{-5}$ to $4.7 \times 10^{-5}$ dyne $/ \mathrm{cm}^{2}$. After $18 \mathrm{~h}$ FSS, HLCs were transferred into a 24-well plate for further analysis. Cytochrome P450 (Cyp) metabolic activities of two enzymes, Cyp1A2 and Cyp2D6, were measured to evaluate the effect of FSS on HLC phenotype. Cyp1A2 activity was significantly increased fivefold over controls in $2 \mathrm{D}$ cultures at $4.7 \times 10^{-5} \mathrm{dyne} / \mathrm{cm}^{2}$ (Fig. 1a). 


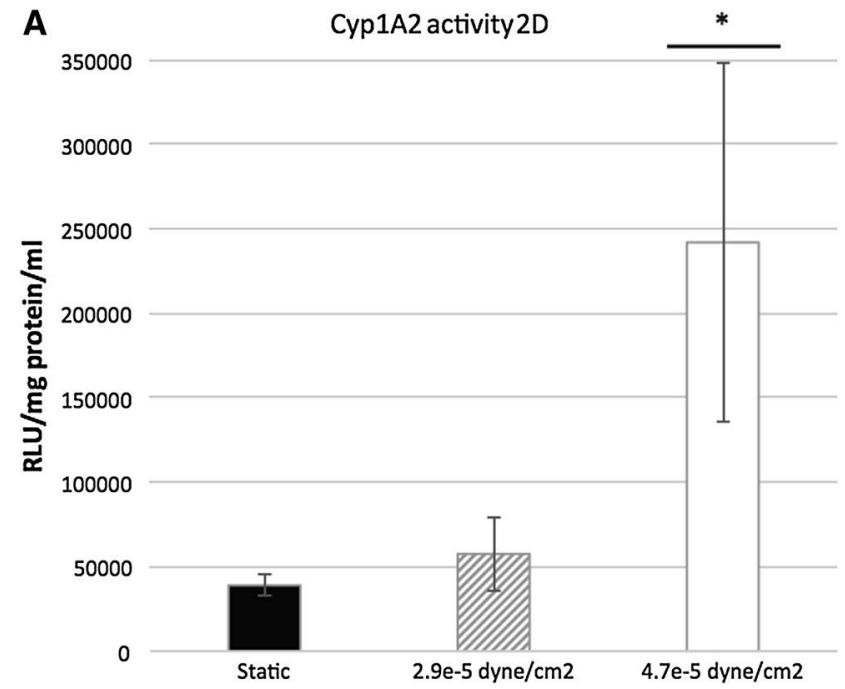

Fig. 1 a Cyp1A2 metabolic activity of monolayer hepatocyte-like cells (HLCs) under static conditions (black columns) and following fluid shear stress (FSS) of $2.9 \times 10^{-5}$ dynes $/ \mathrm{cm}^{2}$ (shaded columns) and $4.7 \times 10^{-5}$ dynes $/ \mathrm{cm}^{2}$ (white columns). Data are presented as mean of three independent experiments. Error bars represent the standard deviation (SD). ${ }^{*} p<0.05, * * p<0.01$; two-tailed $t$ test anal-

To assess Cyp2D6 activity, a compound (BMS 827278) which requires Cyp2D6 metabolic activity to convert it to a toxic end point was employed. Post-exposure to BMS 827278 , cell viability was measured and compared to the DMSO vehicle control. As expected, microscopic and quantitative ATP analysis revealed that BMS 827278 had a detrimental effect on the viability of HLCs (Medine et al. 2013; Villarin et al. 2015). Notably, HLC viability was significantly decreased by a further fivefold and ninefold in response to FSS at $2.9 \times 10^{-5}$ and $4.7 \times 10^{-5}$ dyne $/ \mathrm{cm}^{2}$, respectively (Fig. 2a). This demonstrates that FSS was an important physiological stimulus for metabolic activity in human hepatocyte models derived from pluripotent stem cells.

To examine the effect of FSS on 3D-cultured HLCs, hepatic spheroids were seeded on Matrigel-coated Thermanox $^{\mathrm{TM}}$ coverslips prior to transfer into the Quasi-Vivo ${ }^{\circledR}$ system. Anchored spheroids were then exposed to FSS of $2.9 \times 10^{-5}$ and $4.7 \times 10^{-5} \mathrm{dyne} / \mathrm{cm}^{2}$ for $18 \mathrm{~h}$. Contrary to 2D-cultured HLCs, metabolic activity of Cyp1A2 decreased significantly following exposure to $4.7 \times 10^{-5}$ dyne $/ \mathrm{cm}^{2}$ by approximately twentyfold (Fig. 1b). Similar to 2D-cultured HLCs, 3D spheroids showed sensitivity to BMS 827278 which was marginally enhanced following FSS. The 3D spheroids cultured under static condition showed over a threefold increase in sensitivity to BMS 827278 in comparison with $2 \mathrm{D}$ cultures. This suggests that 3D cultures displayed an improved basal level of Cyp2D6 activity (Fig. 2b). In addition to metabolic activity, we also

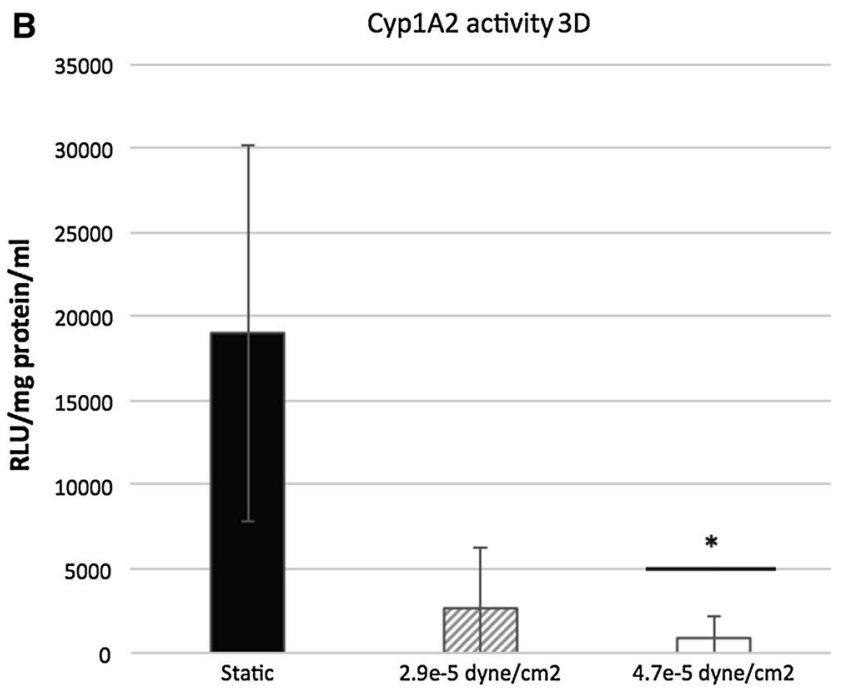

ysis. b Cyp1A2 metabolic activity of 3D HLCs under static conditions (black columns) and following FSS of $2.9 \times 10^{-5}$ dynes $/ \mathrm{cm}^{2}$ (shaded columns) and $4.7 \times 10^{-5}$ dynes $/ \mathrm{cm}^{2}$ (white columns). Data are presented as mean of three independent experiments. Error bars represent SD. $* p<0.05,{ }^{*} p<0.01$; two-tailed $t$ test analysis

measured serum protein production under static conditions and flow. The production of albumin remained constant in 2D and 3D models under static conditions and in response to FSS (Fig. 3a). In contrast, the production of alpha-fetoprotein (AFP) was significantly reduced in $2 \mathrm{D}$, but not $3 \mathrm{D}$ HLCs following exposure to FSS (Fig. 3b).

\section{Discussion}

The liver is a highly vascular organ, processing $25-30 \%$ of the total blood volume at any given time (Bradley et al. 1945). Arterial and venous blood enters the liver lobes, flowing through the sinusoids towards the central vein (Ebrahimkhani et al. 2014). Sinusoids commonly have diameters ranging from $7 \mu \mathrm{m}$ in the periportal to $15 \mu \mathrm{m}$ in pericentral regions (Vollmar and Menger 2009) and experience fluid shear stresses between $0.1-0.5 \mathrm{dyne} / \mathrm{cm}^{2}$. This is lower than fluid shear stresses observed in other capillary systems, typically around 15 dyne $/ \mathrm{cm}^{2}$ (Koutsiaris et al. 2007). While it is difficult to gauge the exact level of shear stress experienced by hepatocytes (LeCluyse et al. 2012), it has been estimated to be several orders of magnitude lower than the level of sinusoidal shear stress.

Despite the evidence supporting the importance of FSS in cell biology, few studies have addressed this in the hepatocyte. In pioneering work, Mufti and colleagues showed transient increase in AhR-driven Cyp1 A1 expression and function following exposure to FSS (Mufti 


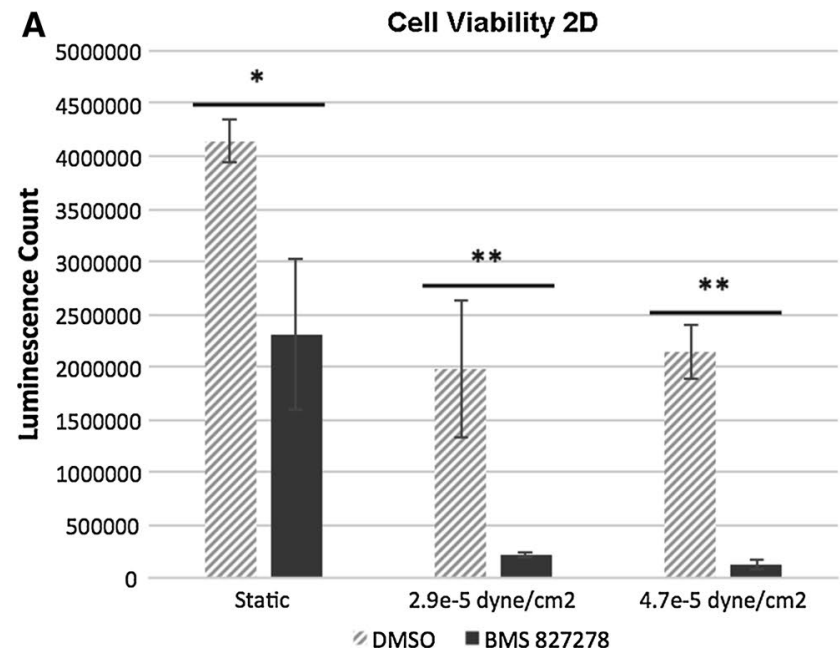

Fig. 2 a Cell viability assay of monolayer cultured HLCs following exposure to DMSO and BMS 827278 under static conditions or following exposure to fluid shear stress (FSS). Data are presented as mean of three independent experiments. Error bars represent the standard deviation (SD). ${ }^{*} p<0.05, * * p<0.01$; two-tailed $t$ test

A

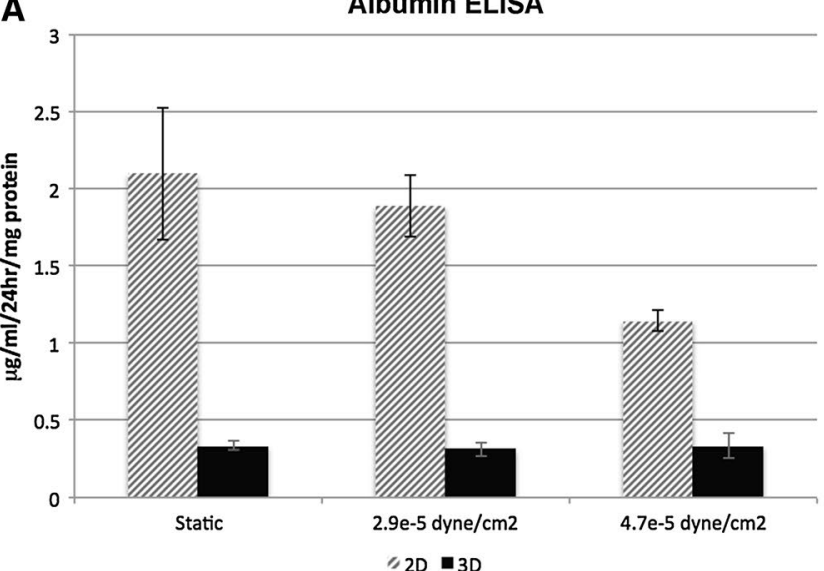

Fig. 3 a HLC albumin production was measured by ELISA under static conditions or following exposure to fluid shear stress (FSS). Albumin secretion is expressed as micrograms of albumin (ALB) $\mathrm{ml}^{-1}$ per $24 \mathrm{~h}$ per mg protein. Data are presented as mean of three independent experiments. Error bars represent the standard deviation (SD). ${ }^{*} p<0.05,{ }^{* *} p<0.01$; two-tailed $t$ test analysis. b HLC AFP

et al. 1995). A later study suggested a potential role of arachidonic acid in the induction of Cyp1A1 in HepG2 cells under hydrodynamic stimulation (Mufti and Shuler 1996). Along similar lines, the induction of Cyp1A1 activity has also been reported in rat hepatocytes (Gebhardt et al. 1996; Roy et al. 2001). More recently, genes

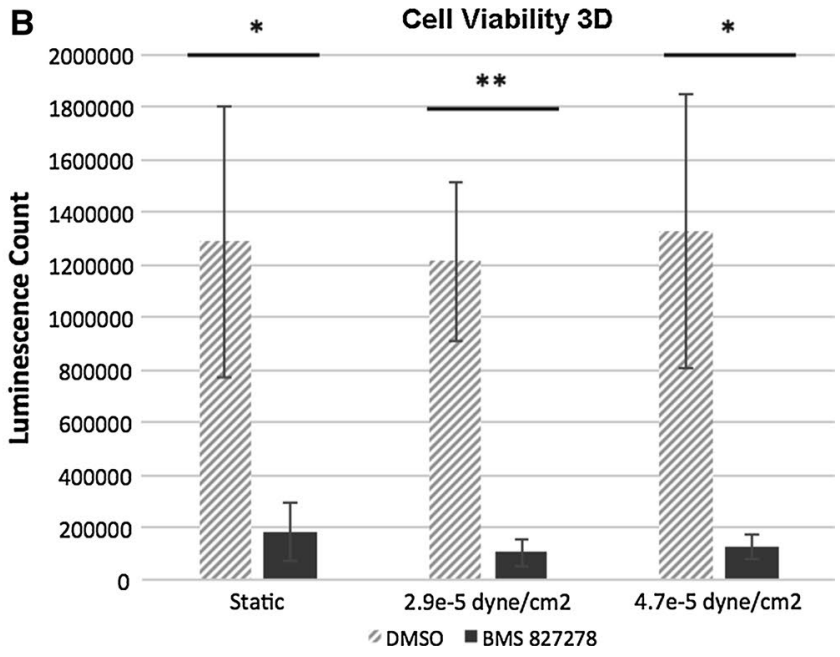

analysis. b Cell viability assay of 3D cultured HLCs following exposure to DMSO and BMS 827278 under static conditions or following exposure to FSS. Data are presented as mean of three independent experiments. Error bars represent SD. ${ }^{*} p<0.05$, ${ }^{*} p<0.01$; twotailed $t$ test analysis

B

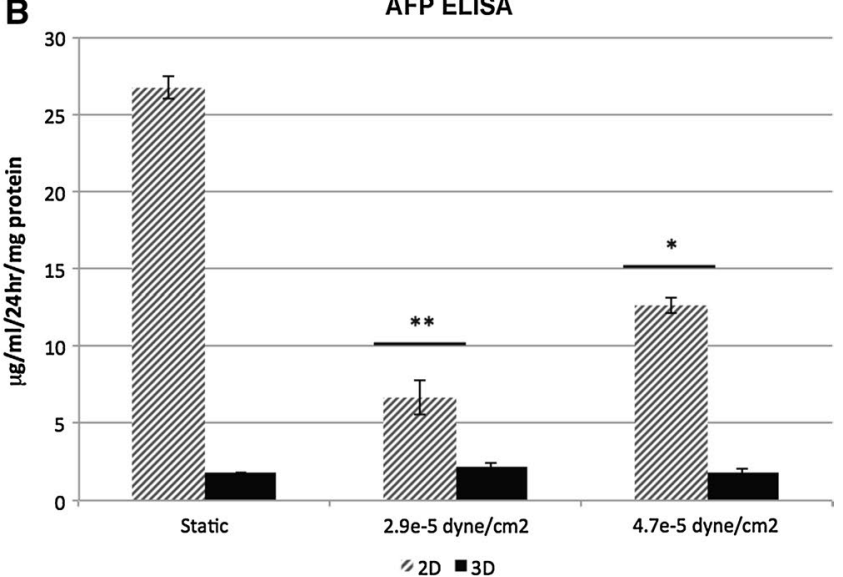

production was measured by ELISA under static conditions or under FSS. Alpha-fetoprotein (AFP) secretion is expressed as micrograms of AFP ml ${ }^{-1}$ per $24 \mathrm{~h}$ per mg protein. Data are presented as mean of three independent experiments. Error bars represent SD. $* p<0.05$, ** $p<0.01$; two-tailed $t$ test analysis

involved in human drug metabolism, including CYP1A1, 1A2, 2B6, 2C9 and 3A4, were shown to be positively regulated by flow (Vinci et al. 2011). Our data provide further evidence to support the importance of FSS on HLC metabolic function and serum protein secretion (Figs. 1, $2,3)$. 


\section{Conclusion}

In conclusion, a more active and predictive hepatocyte model was created after exposure to fluid shear stress. We believe that this demonstrates the importance of adding back human physiology to improve somatic cell-phenotype in vitro.

Acknowledgments Drs. Hay and Rashidi were supported with awards from the UK Regenerative Medicine Platform (MRC MR/ L022974/1) and the NC3Rs CrackIT scheme.

Open Access This article is distributed under the terms of the Creative Commons Attribution 4.0 International License (http://creativecommons.org/licenses/by/4.0/), which permits unrestricted use, distribution, and reproduction in any medium, provided you give appropriate credit to the original author(s) and the source, provide a link to the Creative Commons license, and indicate if changes were made.

\section{References}

Bao G, Suresh S (2003) Cell and molecular mechanics of biological materials. Nat Mater 2(11):715-725. doi:10.1038/nmat1001

Bradley SE, Ingelfinger FJ et al (1945) The estimation of hepatic blood flow in man. J Clin Investig 24:890-897

Cameron K, Tan R, Schmidt-Heck W et al (2015) Recombinant Laminins drive the differentiation and self-organization of hESC-derived hepatocytes. Stem Cell Rep 5(6):1250-1262. doi:10.1016/j.stemcr.2015.10.016

Ebrahimkhani MR, Neiman JA, Raredon MS, Hughes DJ, Griffith LG (2014) Bioreactor technologies to support liver function in vitro. Adv Drug Deliv Rev 69-70:132-157. doi:10.1016/j. addr.2014.02.011

Freund JB, Goetz JG, Hill KL, Vermot J (2012) Fluid flows and forces in development: functions, features and biophysical principles. Development 139(7):1229-1245. doi:10.1242/dev.073593

Gebhardt R, Wegner H, Alber J (1996) Perifusion of co-cultured hepatocytes: optimization of studies on drug metabolism and cytotoxicity in vitro. Cell Biol Toxicol 12(2):57-68. doi:10.1007/ Bf00143356

Godoy P, Schmidt-Heck W, Natarajan K et al (2015) Gene networks and transcription factor motifs defining the differentiation of stem cells into hepatocyte-like cells. J Hepatol 63(4):934-942. doi:10.1016/j.jhep.2015.05.013

Hahn C, Schwartz MA (2009) Mechanotransduction in vascular physiology and atherogenesis. Nat Rev Mol Cell Biol 10(1):53-62. doi: $10.1038 / \mathrm{nrm} 2596$

Hildebrandt F, Benzing T, Katsanis N (2011) Mechanisms of disease: ciliopathies. New Engl J Med 364(16):1533-1543

Koutsiaris AG, Tachmitzi SV, Batis N et al (2007) Volume flow and wall shear stress quantification in the human conjunctival capillaries and post-capillary venules in vivo. Biorheology 44(5-6):375-386

LeCluyse EL, Witek RP, Andersen ME, Powers MJ (2012) Organotypic liver culture models: meeting current challenges in toxicity testing. Crit Rev Toxicol 42(6):501-548. doi:10.3109/10408444.2012.682115

Mammoto T, Ingber DE (2010) Mechanical control of tissue and organ development. Development 137(9):1407-1420. doi:10.1242/dev.024166

Medine CN, Lucendo-Villarin B, Storck C et al (2013) Developing high-fidelity hepatotoxicity models from pluripotent stem cells. Stem Cells Transl Med 2(7):505-509. doi:10.5966/ sctm.2012-0138

Mufti NA, Shuler ML (1996) Possible role of arachidonic acid in stress-induced cytochrome P450IA1 activity. Biotechnol Progress 12(6):847-854. doi:10.1021/bp960067j

Mufti NA, Bleckwenn NA, Babish JG, Shuler ML (1995) Possible involvement of the Ah receptor in the induction of cytochrome P-450IA1 under conditions of hydrodynamic shear in microcarrier-attached hepatoma cell lines. Biochem Biophys Res Commun 208(1):144-152. doi:10.1006/bbrc.1995.1316

Park J, Li Y, Berthiaume F, Toner M, Yarmush ML, Tilles AW (2008) Radial flow hepatocyte bioreactor using stacked microfabricated grooved substrates. Biotechnol Bioeng 99(2):455-467. doi:10.1002/bit. 21572

Rashidi H, Yang J, Shakesheff KM (2014) Surface engineering of synthetic polymer materials for tissue engineering and regenerative medicine applications. Biomater Sci UK 2(10):1318-1331. doi:10.1039/c3bm60330j

Roy P, Washizu J, Tilles AW, Yarmush ML, Toner M (2001) Effect of flow on the detoxification function of rat hepatocytes in a bioartificial liver reactor. Cell Transplant 10(7):609-614

Shvartsman I, Dvir T, Harel-Adar T, Cohen S (2009) Perfusion cell seeding and cultivation induce the assembly of thick and functional hepatocellular tissue-like construct. Tissue Eng Part A 15(4):751-760. doi:10.1089/ten.tea.2008.0024

Szkolnicka D, Zhou W, Lucendo-Villarin B, Hay DC (2013) Pluripotent stem cell-derived hepatocytes: potential and challenges in pharmacology. Annu Rev Pharmacol Toxicol 53:147-159. doi:10.1146/annurev-pharmtox-011112-140306

Szkolnicka D, Farnworth SL, Lucendo-Villarin B et al (2014a) Deriving functional hepatocytes from pluripotent stem cells. Curr Protoc Stem Cell Biol 30:1G.5.1-1G.5.12. doi:10.1002/9780470151808.sc01g05s30

Szkolnicka D, Farnworth SL, Lucendo-Villarin B et al (2014b) Accurate prediction of drug-induced liver injury using stem cell-derived populations. Stem Cells Transl Med 3(2):141-148. doi:10.5966/sctm.2013-0146

Tilles AW, Baskaran H, Roy P, Yarmush ML, Toner M (2001) Effects of oxygenation and flow on the viability and function of rat hepatocytes cocultured in a microchannel flat-plate bioreactor. Biotechnol Bioeng 73(5):379-389

Tzima E, del Pozo MA, Shattil SJ, Chien S, Schwartz MA (2001) Activation of integrins in endothelial cells by fluid shear stress mediates Rho-dependent cytoskeletal alignment. EMBO J 20:4639-4647

Tzima E, Irani-Tehrani M, Kiosses WB et al (2005) A mechanosensory complex that mediates the endothelial cell response to fluid shear stress. Nature 437(7057):426-431

Villarin BL, Cameron K, Szkolnicka D et al (2015) Polymer supported directed differentiation reveals a unique gene signature predicting stable hepatocyte performance. Adv Healthc Mater 4(12):1820-1825. doi:10.1002/adhm.201500391

Vinci B, Duret C, Klieber S et al (2011) Modular bioreactor for primary human hepatocyte culture: medium flow stimulates expression and activity of detoxification genes. Biotechnol J 6(5):554 564. doi:10.1002/biot.201000326

Vollmar B, Menger MD (2009) The hepatic microcirculation: mechanistic contributions and therapeutic targets in liver injury and repair. Physiol Rev 89(4):1269-1339. doi:10.1152/ physrev.00027.2008

White CR, Frangos JA (2007) The shear stress of it all: the cell membrane and mechanochemical transduction. Philos Trans R Soc Lond B Biol Sci 362(1484):1459-1467. doi:10.1098/ rstb.2007.2128 